\title{
DE COORDINACIÓN INSTITUCIONAL EN LA IMPLEMENTACIÓN DE POLÍTICAS SOCIALES. EL CASO DE LAS POLÍTICAS DE CUIDADO INFANTIL EN ARGENTINA
}

\author{
Marzonetto, Gabriela
}

\section{Gabriela Marzonetto}

gabrielamarzonetto@gmail.com

CONICET, Argentina

\author{
Documentos y Aportes en Administración Pública y \\ Gestión Estatal \\ Universidad Nacional del Litoral, Argentina \\ ISSN: 1666-4124 \\ ISSN-e: 1851-3727 \\ Periodicidad: Semestral \\ vol. 20, núm. 35, 2020 \\ jvigil@fce.unl.edu.ar
}

Recepción: 12 Agosto 2020

Aprobación: 21 Enero 2021

URL: http://portal.amelica.org/ameli/jatsRepo/502/5022249002/ index.html

DOI: https://doi.org/DOI 10.14409/daapge.2020.35.e0002

Para citar este artículo:: Marzonetto, G. (2020) "Propuesta de modelo de análisis de coordinación institucional en la implementación de políticas sociales. El caso de las políticas de cuidado infantil en argentina." DAAPGE Vol. 20, $\mathrm{N}^{\circ} 35,2020$, pp. 18-35. UNL, Santa Fe, Argentina.
Resumen: En el último tiempo ha ganado espacio en el debate público la demanda por políticas de cuidado, en especial de niños y niñas pequeñas, entendiendo que esto repercutiría positivamente sobre su bienestar y en las posibilidades laborales de las madres. Entre estas políticas se encuentran las que garantizan tiempo de cuidado, dinero para cuidar y espacios de cuidado, por lo que implica la articulación entre programas de licencias, transferencias y espacios de desarrollo infantil. Con ello, lograr el propósito de resolver el problema del cuidado infantil a partir de estas políticas resulta en un desafío complejo donde se articulan procesos de coordinación horizontal y vertical para su gestión. En este trabajo se busca analizar el nivel de coordinación institucional de las políticas de cuidado infantil en Argentina, y a partir de ello identificar las principales dificultades que se encuentran para diseñar una estrategia integral para su abordaje. A tales fines se propone un modelo de análisis de la coordinación de programas. A partir del análisis desarrollado se encuentra que en el país los programas de cuidado infantil presentan una coordinación institucional incipiente y débil.

Palabras clave: políticas de cuidado infantil, coordinación institucional, diseños de política públicas, integralidad, fragmentación.

Abstract: In recent times, the demand for child care policies has upraised in the public debate, understanding that this would have a positive impact on children well-being and on the employment possibilities of their mothers. Childcare policies are those that guarantee time, money and spaces for care, which implies the articulation between parental leaves policies, cash transfers programs and early child education and care services. With this, to solve the child care problem based on these policies programs results in a complex challenge of institutional coordination. This paper seeks to analyze the level of institutional coordination of child care policies in Argentina, and to identify the main difficulties in order to design a comprehensive strategy of childcare. For this purpose we create a model of analysis of the level of coordination among programs. Based on the analysis developed, we found that the childcare programs in the country present incipient and weak institutional coordination features. 
Keywords: childcare policies, institutional coordination, policy design, fragmentation, integrality.

\section{Introducción}

Las políticas sociales destinadas a resolver riesgos sociales y mejorar el bienestar de la población tienen la particularidad de que, desde su formulación hasta su implementación, requieren de la interacción de distintos organismos tanto a nivel horizontal como vertical. Esto es así debido a que, por un lado, la complejidad de los problemas sociales rara vez puede ser abordada sectorialmente; y por otro lado, a que toda actuación pública implica la presencia de una decisión política y un ejercicio a nivel territorial. Esto último puede darse en el mismo nivel de gobierno, pero en general, para el caso de políticas nacionales, necesariamente implica un proceso de gestión intergubernamental y de acción intersectorial. En este sentido, ante la cada vez más creciente búsqueda de respuestas integrales a problemas sociales, resulta importante preguntarnos en qué medida en los procesos de formulación e implementación de políticas sociales se generan instancias intergubernamentales (tanto a nivel horizontal como vertical).

En esta línea, encontramos que en el último tiempo en Argentina ha ganado repercusión pública el debate sobre la necesidad de abordar desde el Estado el problema del cuidado, como un nuevo riesgo social, de manera sistemática, integral y con perspectiva de género. ${ }^{1}$ Es decir, que requiere de un abordaje intersectorial, cuestión que lleva implícita la necesidad de la coordinación entre programas para el logro de la integralidad perseguida.

En referencia a la cuestión del cuidado, se lo problematiza entendiendo que las tareas que involucra son esenciales para la sostenibilidad de la vida (Carrasco 2003; Tronto 1987). A partir de esto, se demandan políticas públicas específicas que atiendan a esta problemática que reproduce desigualdades de género y socioeconómicas (Rodríguez Enríquez y Pautassi, 2014). ${ }^{2}$

En el caso de los servicios y prestaciones destinados a la primera infancia (desde su nacimiento y hasta los 5 años), que abordaremos aquí, esta tienen por finalidad específica la inversión social, entendiendo que en los primeros años de vida se juegan las posibilidades a futuro de esos niños; a la vez que buscan conciliar estos aspectos con la participación en el mercado laboral de sus responsables -sobre todo de las madres- (Esping-Andersen 2010; EspingAndersen y Palier 2011; Morel, Palier, y Palme 2012; Rodriguez Enríquez y Pautassi 2014). Por ello, la literatura especializada sugiere que para hacer frente al problema del cuidado infantil es necesario contar con políticas públicas que permitan resolver tres aspectos: tiempos de cuidado (licencias por nacimiento y cuidados), infraestructura y espacios de cuidado y dinero para la crianza(Blofield y Martínez Franzoni 2014; Ellingsaeter 1999; Orloff 2006; Rossel y Hernandez 2013).

Los estudios en la materia plantean que en la medida en que estos programas se encuentren articulados permiten contribuir a la corresponsabilidad de los cuidados entre las familias y el Estado. Por ello, se parte del supuesto 
de que si estas políticas se encuentran integradas permiten des-familiarizar parcialmente el cuidado. Mientras que en los casos en que las políticas se encuentran fragmentadas, estas pueden cumplir sus objetivos específicos, pero no contribuyen a dar respuestas a la organización de los cuidados.

En este trabajo sostenemos que en Argentina existen respuestas estatales al cuidado - más allá de cuestionar su grado de eficiencia, extensión y de acceso- pero que debido a la falta de coordinación entre programas, no permiten resolverlo integralmente. En esta línea, buscamos analizar el nivel de coordinación institucional entre los programas que responden a los tres componentes de cuidado infantil (tiempos, servicios y dinero) a partir de un modelo creado a tal fin, en base a aportes de trabajos teóricos clásicos y del análisis documental de información oficial, leyes, decretos reglamentarios, registros administrativos e informes de gestión de los distintos programas nacionales seleccionados. Consideramos que este modelo puede permitirnos identificar potenciales desafío de cara a la creación de un sistema de cuidados.

El documento se divide en cuatro secciones, incluida esta introducción. En la sección 2 se presenta la propuesta de modelo de análisis a partir de las discusiones teóricas en torno a la coordinación institucional. En la sección 3 se presentan los resultados del trabajo, donde por un lado se describen sucintamente los programas de cuidado infantil en Argentina (a nivel nacional), y luego con el modelo analítico propuesto se analiza el grado de coordinación institucional que presentan. Finalmente, la sección 4 presenta la discusión sobre los hallazgos, potencialidades y las limitaciones del análisis.

\section{Marco analítico}

Dada la complejidad de los problemas sociales estos requieren de intervenciones que superen los clásicos nichos de abordaje sectorial, lo que necesariamente implica un proceso de gestión intergubernamental (Agranoff 1997; O'Toole 2007). La acción intersectorial, tal como denomina Cunill-Grau a este tipo de abordaje, puede ser entendida como la tendencia a la re conceptualización de lo social, desde un enfoque multidimensional y centrado en los derechos, que implica ir un paso más allá de la simple agregación de acciones en conjunto entre diferentes sectores de gobierno (Acuña y Repetto, 2006; Cunill-Grau, 2016).

Cunill-Grau (2016), sostiene que este modo de entender la intersectorialidad se basa en dos premisas fundamentales: La primera es que la integración entre sectores hace posible la búsqueda de soluciones integrales. Esto le asigna una connotación política, al suponer que todas las políticas de enfoques integrales deben ser planificadas y ejecutadas intersectorialmente. La segunda premisa es que la integración entre sectores permite que las diferencias en capacidades y especificidades se puedan utilizar de manera más eficiente para la resolución de los problemas. De este modo, la intersectorialidad implica la construcción de una visión holística desde los organismos gubernamentales sobre los problemas sociales, y si bien no es sinónimo de coordinación institucional, esta última es un requisito indispensable para su logro. 


\subsection{Coordinación institucional}

Guy Peters (1998a) plantea que "la coordinación institucional refiere a la necesidad de asegurar que las organizaciones - públicas y privadas-, encargadas de la prestación de políticas públicas trabajen de manera conjunta sin generar redundancia ni brechas en la provisión de servicios" $(1998,5) \cdot{ }^{3}$ La misma se torna necesaria al momento de delimitar acciones intersectoriales para el abordaje de un problema social multidimensional.

En los procesos de formulación de políticas públicas intervienen numerosos actores y organismos del sector público -pero también podemos encontrar la intervención del sector privado empresarial y comunitario-, que deben seguir cursos de acción coordinados por el ente (actor/organismo) que asuma el rol de agente catalítico (o de secretaría ejecutiva de las instancias de coordinación), con la suficiente autoridad para convocar y coordinar a todas las partes relevantes. Cunill-Grau (2005), sostiene que "la sostenibilidad de la coordinación horizontal es afectada tanto por la jerarquía formal del ente que actúa como secretaría ejecutiva de las instancias coordinadoras, como también por las consecuencias simbólicas que deriven de su acción” $(2005,46)$.

Es decir que quien asuma este rol estará determinado por la naturaleza del problema en cuestión, por su legitimidad frente al resto de los entes intervinientes, por su poder de negociación y por sus capacidades técnicas, administrativas y presupuestarias para emprender la tarea. Por lo cual, no resulta tan simple designar un agente central, y no todo es positivo en materia de acción intersectorial, puesto que si bien las diferencias entre los sectores dotan de racionalidad y eficiencia al diseño e implementación de las políticas públicas, a su vez "las diferencias percibidas de poder son uno de sus obstáculos" (CunillGrau 2005, 46), que nos recuerdan que las disputas por el poder entre los entes estatales y los actores intervinientes siempre están presentes.

Esto último adquiere notoriedad sobre todo cuando hablamos de agencias estatales con recursos humanos y económicos limitados, y al hecho de que la agencia que actúe como secretaría ejecutiva será quien obtenga los réditos por la gestión integral de la política en cuestión -aun cuando otras agencias hayan participado e involucrado recursos propios- (O'Toole 2007). Por esta razón hay que considerar la posibilidad de que desde estas agencias de rol secundario, no se les otorgue prioridad a las actividades de coordinación. Por otro lado, la coordinación implica la pérdida de autonomía de las agencias, y por consiguiente al coordinar se cede poder y libertad de acción (Acuña 2017). Frente a este escenario el agente catalizador tiene la tarea de utilizar mecanismos integradores a través de los cuales dote de "racionalidad integradora" a la acción intersectorial para otorgar viabilidad técnica y política al proceso de formulación de la política social.

Por su parte, cuando la coordinación no se logra, esto puede afectar a la dotación de aquellos bienes y servicios que el Estado debe proveer a la ciudadanía (Peters, 1998a), cuestión que se traduce en un descrédito sobre la capacidad de las instituciones públicas. Paralelamente, cuando hay agencias estatales que trabajan sobre el mismo grupo poblacional, muchas veces, en lugar de coordinar acciones se disputan los recursos, generando superposición o contradicción en las intervenciones, generando costos económicos y problemas de eficiencia (Peters 
1998a, 3). En suma, los problemas de coordinación aumentan los costos de las agencias estatales y reducen la capacidad creativa para la intervención estatal (1998a, 3).

A partir de esto es importante señalar que la coordinación institucional no se da siempre en el mismo sentido, al respecto podemos identificar las diferentes formas que puede adoptar: (i) coordinación intersectorial (horizontal), que involucra los problemas de coordinación entre agencias del mismo nivel de gobierno, y los que se generan hacia dentro de las mismas.(ii)Coordinación intergubernamental, referida a la articulación entre los distintos niveles de gobierno, que genera mayores conflictos en los casos de países federales donde todos los niveles de gobierno intervienen en la implementación de casi todas las áreas de políticas (Peters 1998a, 22).E, (iii) integración depoliticas en el sentido de la complementariedad de programas de políticas públicas desde áreas diferentes (Licha y Molina, 2006).

Estas formas de coordinación toman diferentes matices en base a las características institucionales, entre ellos, la forma de organización política y administrativa y los procesos de centralización-descentralización. Asimismo, en la mayoría de las ocasiones, se dan conjuntamente, generando lo que podríamos llamar "coordinación anidada" (Acuña 2017), en el sentido en que se presentan situaciones (y problemas) de coordinación intersectorialmente (horizontal), pero también entre jurisdicciones de manera vertical, donde entra en juego la gestión intergubernamental multinivel.

Siguiendo la metáfora de los juegos anidados de George Tsebelis $(1990)^{4}$ consideramos que la noción de coordinación anidada permite comprender la coordinación institucional en su complejidad. Para ello supone que los desafíos y estrategias de coordinación no se dan en función de una sola de estas situaciones (ej. analizando sólo el problema de coordinación horizontal), sino considerando que una de las formas de coordinación afecta sobre las otras, que a su vez están presentes en el proceso de formulación de las políticas (ej. la coordinación vertical para la implementación de la política integral e intersectorial) (Acuña 2017).

Tomando estos aspectos en consideración, y con el objeto de construir un modelo que permita medir el grado de coordinación institucional para la implementación de políticas de cuidado infantil, adoptamos la propuesta de Guy Peters (1998b) a través de la cual el autor establece cuatro posibles niveles de coordinación:

a) Primer nivel: coordinación negativa, en el cual las organizaciones gubernamentales no tienen interacción en la implementación de programas.

b) Segundo nivel: coordinación positiva, en la cual no sólo se genera un reconocimiento de los otros programas que se llevan a cabo, sino que se trabaja en conjunto para mejorar los servicios ofrecidos, no obstante esto cada organización mantiene sus propias metas particulares.

c) Tercer nivel: Integración de politicas, donde se coordina la provisión de los servicios brindados por las distintas organizaciones públicas y también las metas perseguidas por las mismas. En este nivel deviene necesaria la negociación y la imposición de una autoridad (agente catalítico) desde 
el gobierno central. Este nivel es más difícil de lograrse en términos políticos.

d) Cuarto y último nivel: desarrollo de estrategias de gobierno donde se generen además de acuerdos sustanciales en torno a los objetivos de las organizaciones, una visión estrategia sobre el futuro de las políticas a llevar a cabo. Este nivel de estrategia gubernamental en el caso de lograrse, genera un movimiento del proceso de formulación de políticas hacia la búsqueda de soluciones integrales de los problemas públicos y hacia mejores respuestas ante las demandas futuras.

Si bien estas categorías resultan útiles para medir el nivel de coordinación horizontal (como primera forma de coordinación institucional), consideramos que por sí solas no permiten evaluar el proceso de coordinación vertical (la cual suponemos que se da en un segundo momento, y responde a una instancia previa de coordinación), y por consiguiente tampoco los potenciales problemas de coordinación anidada. Ante esto, para complementar la construcción del modelo de análisis para la medición de la coordinación institucional se incorpora una dimensión referida a la descentralización, que permite analizar las posibilidades de coordinación intergubernamental.

\subsection{La descentralización de las politicas públicas}

La descentralización, en el caso particular de las políticas sociales, es un proceso de reforma donde los niveles más bajos de gobierno son los principales depositarios de las responsabilidades, recursos y autoridades transferidas desde los niveles más altos de gobierno (Falleti 2005, 328-29).

Este tipo de entramado institucional que "designa" a qué jurisdicción corresponde cada política social, afecta de modo sustantivo en el diseño e implementación de las políticas de cuidado, puesto que impone la necesidad de tomar acciones intersectoriales más allá de los límites jurisdiccionales de los organismos estatales. Lo que supone una creciente cantidad de actores en el proceso de formulación de políticas, y se traduce en mayor cantidad de actores que a su vez presentan diferentes visiones, objetivos y restricciones que pueden afectar al proceso de implementación de la política (O'Toole 2007, 144).

Esto implica que las relaciones intergubernamentales, influenciadas por mecanismos informales, pero sobre todo constreñidas por las instituciones (i.e. límites funcionales de las jurisdicciones, procesos de descentralización/ centralización), son muy importantes para el éxito de las políticas sociales que presentan múltiples aristas y que por lo tanto son de diseño e implementación compleja y requieren de la gestión intergubernamental (Agranoff 1993; Campbell 2002). A partir de estas consideraciones, se presenta una propuesta de evaluación del nivel de coordinación institucional para políticas sociales, con foco en las políticas de cuidado infantil.

\subsection{Propuesta de evaluación del nivel de coordinación institucional entre politicas}

El esquema diseñado para evaluar el nivel de coordinación institucional entre políticas, establece que el mismo puede ser: nulo, incipiente y débil, incipiente y 
fuerte, consolidado y débil, o consolidado y fuerte. Estas categorías se construyeron tomando en consideración la posibilidad de que los gobiernos puedan garantizar la estabilidad de la coordinación en base al logro de acuerdos y consensos entre los múltiples actores intersectoriales e intergubernamentales intervinientes, $\mathrm{y}$ la institucionalidad en el sentido del nivel de legalidad de los acuerdos de coordinación. (Ver cuadro 1)

\section{Cuadro 1.}

\begin{tabular}{|l|l|l|l|}
\hline $\begin{array}{l}\text { Tipo de } \\
\text { estabilidad } \\
\text { de la } \\
\text { coordinación }\end{array}$ & \multicolumn{3}{|c|}{$\begin{array}{l}\text { Institucionalidad de la } \\
\text { coordinación }\end{array}$} \\
\cline { 2 - 4 } & $\begin{array}{l}\text { Acuerdos } \\
\text { informales }\end{array}$ & $\begin{array}{l}\text { Acuerdos } \\
\text { formales }\end{array}$ \\
\cline { 2 - 4 } & $\begin{array}{l}\text { Estabilidad } \\
\text { basada en } \\
\text { decisión del } \\
\text { gobierno central }\end{array}$ & $\begin{array}{l}\text { Incipiente y } \\
\text { débil }\end{array}$ & $\begin{array}{l}\text { Incipiente y } \\
\text { fuerte }\end{array}$ \\
\cline { 2 - 4 } & $\begin{array}{l}\text { Estabilidad } \\
\text { basada en } \\
\text { consenso }\end{array}$ & $\begin{array}{l}\text { Consolidada y } \\
\text { débil }\end{array}$ & $\begin{array}{l}\text { Consolidada y } \\
\text { fuerte }\end{array}$ \\
\hline
\end{tabular}

Niveles de coordinación institucional

Elaboración propia

En nuestro modelo tomaremos dos momentos para analizar la capacidad de coordinación institucional. En el primer momento se debe analizar el tipo de coordinación horizontal existente, pudiendo adoptar para las diferentes dimensiones de análisis los valores: nula, positiva, integración de politicas y desarrollo de estrategias de gobierno, siguiendo la clasificación de Peters (1998b).

Las dimensiones de análisis adoptadas son los referidos a: 1) el proceso de formulación de políticas, tomando en consideración si existieron instancias de comunicación y relaciones intersectoriales en los procesos de diseño, de implementación y en la designación de partidas presupuestarias; 2), la institucionalidad de las relaciones intersectoriales, tomando en consideración la presencia (o no) de un consejo o gabinete interministerial específico; la vigencia, periodicidad e institucionalidad de las reuniones interministeriales en el caso de que estas existan; y si existen marcos legales que establezcan formalmente la necesidad de coordinación institucional entre organismos, para el proceso de formulación e implementación de la política o para la vinculación entre los programas específicos que atañen al mismo problema social.

En un segundo momento se procede a medir el nivel de coordinación vertical, que puede tomar los valores de problemática o no problemática. Para ello se adoptan las mismas dimensiones de análisis que en el caso de la coordinación horizontal, sólo que en lugar de observar piezas de evidencia que identifiquen la presencia y tipo de acción intersectorial en el mismo nivel de gobierno, se busca analizar: (1) si la toma de decisiones sobre el diseño de políticas fue unilateral desde el gobierno central o si hubieron instancias de consenso con los Estados subnacionales, (2) si el tipo de gestión de la implementación es centralizada o descentralizada, (3) si las partidas presupuestarias son de fondos nacionales o federales, (4) si el proceso de formulación de esta política en particular implica una continuación o ruptura con la forma de gestión de otros programas sociales, y (5) la cantidad de puntos y de actores de veto presentes. 
Los cuadros 2 y 3 muestran el desglose de la operacionalización del análisis de la coordinación horizontal y vertical, con sus correspondientes dimensiones y subdimensiones de análisis y los valores que pueden adquirir. 


\section{Cuadro 2.}

\begin{tabular}{|c|c|c|c|}
\hline Dimensión & Sub-dimensión & Indicador & valor \\
\hline \multirow{11}{*}{$\begin{array}{l}\text { Proceso de } \\
\text { formulación de } \\
\text { políticas }\end{array}$} & \multirow{3}{*}{ Diseño } & $\begin{array}{l}\text { Si muestra conocimiento de } \\
\text { otras políticas }\end{array}$ & Positiva \\
\hline & & $\begin{array}{l}\text { Si tienen visión sobre el } \\
\text { problema compartida }\end{array}$ & Positiva \\
\hline & & $\begin{array}{l}\text { Si tienen visión sobre el } \\
\text { problema contradictoria }\end{array}$ & Nula \\
\hline & \multirow{5}{*}{ Implementación } & $\begin{array}{l}\text { Si hay superposición de } \\
\text { objetivos y lo funciones }\end{array}$ & Nula \\
\hline & & $\begin{array}{l}\text { Si hay contradicción de } \\
\text { objetivos y /o funciones }\end{array}$ & Nula \\
\hline & & $\begin{array}{l}\text { Si es conjunta (se decide } \\
\text { trabajar sobre la misma } \\
\text { población con visión sobre } \\
\text { el problema compartido) }\end{array}$ & Positiva \\
\hline & & $\begin{array}{l}\text { Definición de Acción de } \\
\text { Coordinación }\end{array}$ & Positiva \\
\hline & & $\begin{array}{l}\text { Conjunta+ Acción de } \\
\text { Coordinación }\end{array}$ & $\begin{array}{l}\text { Integración } \\
\text { de } \\
\text { políticas }\end{array}$ \\
\hline & \multirow{3}{*}{ Presupuesto } & $\begin{array}{l}\text { Específico de la política } \\
\text { definida con el conjunto de } \\
\text { programas que definieron } \\
\text { Acción de coordinación de } \\
\text { Coordinación Institucional }\end{array}$ & $\begin{array}{l}\text { Desarrollo } \\
\text { de } \\
\text { estrategia } \\
\text { de } \\
\text { gobierno }\end{array}$ \\
\hline & & $\begin{array}{l}\text { El presupuesto es conjunto } \\
\text { pero de fondos } \\
\text { discrecionales de } \\
\text { c/ministerio }\end{array}$ & Positiva \\
\hline & & $\begin{array}{l}\text { Los programas no } \\
\text { comparten partida } \\
\text { presupuestaria entre sí }\end{array}$ & Nula \\
\hline \multirow{12}{*}{ Institucionalidad } & \multirow{2}{*}{$\begin{array}{l}\text { Consejo o gabinete } \\
\text { intersectorial } \\
\text { específico }\end{array}$} & En vigencia & Positiva \\
\hline & & Sin vigencia & Nula \\
\hline & \multirow{6}{*}{$\begin{array}{l}\text { Reuniones } \\
\text { inter-ministeriales }\end{array}$} & En vigencia & $\begin{array}{l}\text { Integración } \\
\text { de } \\
\text { politicas }\end{array}$ \\
\hline & & Sistemáticas & $\begin{array}{l}\text { Des. de } \\
\text { estrategia } \\
\text { de } \\
\text { gobierno }\end{array}$ \\
\hline & & $\begin{array}{l}\text { Asistemáticas (ad hoc por } \\
\text { programa) }\end{array}$ & $\begin{array}{l}\text { Integración } \\
\text { de } \\
\text { políticas }\end{array}$ \\
\hline & & Sin vigencia & Nula \\
\hline & & $\begin{array}{l}\text { Sobre interrelación entre } \\
\text { politicas(condicionalidades) }\end{array}$ & Positiva \\
\hline & & De facto a nivel operativo & Positiva \\
\hline & \multirow{4}{*}{ Legalidad de la CI } & $\begin{array}{l}\text { Normativas y marcos } \\
\text { legales vigentes }\end{array}$ & $\begin{array}{l}\text { Des. } \\
\text { Estrategias } \\
\text { de } \\
\text { gobierno }\end{array}$ \\
\hline & & Coordinación de facto & $\begin{array}{l}\text { Integración } \\
\text { de } \\
\text { políticas }\end{array}$ \\
\hline & & $\begin{array}{l}\text { Establecimiento formal de } \\
\text { Acción de Coordinación }\end{array}$ & $\begin{array}{l}\text { Des. } \\
\text { Estrategias } \\
\text { de } \\
\text { gobierno } \\
\end{array}$ \\
\hline & & $\begin{array}{l}\text { Sin establecimiento de } \\
\text { Acción de Coordinación }\end{array}$ & Positiva \\
\hline
\end{tabular}

Coordinación horizontal: Elementos para su medición 
Elaboración propia en base a: Acuña y Repetto 2006; Cunill-Grau 2005; Peters 1998a, 1998b

\section{Cuadro 3.}

\begin{tabular}{|c|c|c|c|}
\hline Dimensión & Sub-dimensión & Indicador & valor \\
\hline \multirow{8}{*}{$\begin{array}{l}\text { Proceso de } \\
\text { formulación de } \\
\text { políticas }\end{array}$} & \multirow{2}{*}{ Diseño } & \begin{tabular}{|l|} 
Desde el \\
Ejecutivo \\
nacional \\
\end{tabular} & $\begin{array}{l}\text { No } \\
\text { problemática }\end{array}$ \\
\hline & & $\begin{array}{l}\text { Consensuado } \\
\text { con E } \\
\text { Sub-nacionales } \\
\end{array}$ & Problemática \\
\hline & \multirow{3}{*}{ Implementación } & Centralizada & $\begin{array}{l}\text { No } \\
\text { problemática }\end{array}$ \\
\hline & & \begin{tabular}{|l|} 
Descentralizada \\
a provincias \\
\end{tabular} & Problemática \\
\hline & & $\begin{array}{l}\text { Descentralizada } \\
\text { a municipios } \\
\end{array}$ & Problemática \\
\hline & \multirow{3}{*}{ Presupuesto } & $\begin{array}{l}\text { Gobierno } \\
\text { nacional }\end{array}$ & $\begin{array}{l}\text { No } \\
\text { problemática }\end{array}$ \\
\hline & & \begin{tabular}{|l|} 
Gobierno \\
Sub-nacional
\end{tabular} & Problemática \\
\hline & & \begin{tabular}{|l|} 
Gestión \\
asociada
\end{tabular} & Problemática \\
\hline \multirow{4}{*}{ Institucionalidad } & \multirow{2}{*}{$\begin{array}{l}\text { Legado de } \\
\text { política pública } \\
\text { sectorial }\end{array}$} & Continuación & $\begin{array}{l}\text { No } \\
\text { problemática }\end{array}$ \\
\hline & & Ruptura & Problemática \\
\hline & \multirow{2}{*}{$\begin{array}{l}\text { Forma de } \\
\text { gobierno } \\
\text { (cantidad de PV } \\
\text { y AV) }\end{array}$} & $\begin{array}{l}\text { Unitaria (pocos } \\
\text { Puntos de Veto } \\
\text { y Actores de } \\
\text { Veto) }\end{array}$ & $\begin{array}{l}\text { No } \\
\text { problemática }\end{array}$ \\
\hline & & $\begin{array}{l}\text { Federal } \\
\text { (muchos Puntos } \\
\text { de Veto y } \\
\text { Actores de veto) }\end{array}$ & Problemática \\
\hline
\end{tabular}

Coordinación vertical: Elementos para su medición

elaboración propia en base a: Acuña y Repetto 2006; Borja 2007; Falleti 2007; Immergut 2008; Martinez Nogueira 2010; O 'Toole 2007.

A continuación se presenta el esquema final de análisis para evaluar el nivel de coordinación institucional alcanzado en la implementación de políticas sociales. 


\section{Cuadro 4.}

\begin{tabular}{|c|c|c|c|}
\hline $\begin{array}{l}\text { Coordinación } \\
\text { Horizontal }\end{array}$ & Coordinación Vertical & $\begin{array}{l}\text { Coordinación } \\
\text { Institucional }\end{array}$ & $\begin{array}{l}\text { Diseño de la } \\
\text { política de } \\
\text { Cuidado } \\
\end{array}$ \\
\hline Si es Nula & No se establece & Nula & \multirow{3}{*}{ Fragmentado } \\
\hline \multirow[t]{2}{*}{ Si es positiva } & $\begin{array}{l}\text { Se establece desde el gobierno } \\
\text { central sin consenso con } \\
\text { gobiernos subnacionales y no } \\
\text { presenta problemas de arrastre } \\
\text { del tiempo } 1\end{array}$ & $\begin{array}{l}\text { Incipiente y } \\
\text { débil }\end{array}$ & \\
\hline & $\begin{array}{l}\text { Se establece en consenso con } \\
\text { otros niveles jurisdiccionales, } \\
\text { pero no se generaron acuerdos } \\
\text { formales }\end{array}$ & $\begin{array}{l}\text { Consolidada } \\
\text { y débil }\end{array}$ & \\
\hline \multirow{2}{*}{$\begin{array}{l}\text { Si se da } \\
\text { integración } \\
\text { de políticas } \\
\text { (con } \\
\text { designación } \\
\text { de agente } \\
\text { catalítico) } \\
\end{array}$} & $\begin{array}{l}\text { Se establece desde el gobierno } \\
\text { central sin consenso con } \\
\text { gobiernos subnacionales y se } \\
\text { generaron acuerdos formales }\end{array}$ & $\begin{array}{l}\text { Insipiente y } \\
\text { fuerte }\end{array}$ & \multirow{3}{*}{ Integral } \\
\hline & $\begin{array}{l}\text { Se establece en consenso con } \\
\text { otros niveles jurisdiccionales, y } \\
\text { se generaron acuerdos formales }\end{array}$ & $\begin{array}{l}\text { Consolidada } \\
\text { y fuerte }\end{array}$ & \\
\hline $\begin{array}{l}\text { Si se } \\
\text { presenta } \\
\text { como } \\
\text { estrategia de } \\
\text { gobierno }\end{array}$ & $\begin{array}{l}\text { Se establecen acuerdos formales } \\
\text { horizontales y verticales. Se } \\
\text { pueden presentar problemas de } \\
\text { Coordinación Vertical, de } \\
\text { viabilidad técnica }\end{array}$ & $\begin{array}{l}\text { Consolidada } \\
\text { y fuerte }\end{array}$ & \\
\hline
\end{tabular}

Esquema para evaluar el nivel de coordinación institucional Elaboración propia.

\section{El diseño de las políticas de cuidado infantil en Argentina y su capacidad de coordinación}

En el caso del diseño de políticas de cuidado infantil, consideramos que estos pueden tomar diferentes formas en base a los modelos de cuidado que reproduzcan ${ }^{5}$ y a la capacidad de coordinación entre los sectores intervinientes en el proceso de su formulación. La tipología elaborada sugiere que el diseño de las políticas de cuidado puede variar entre aquellos más integrales o más fragmentados.

Los diseños integrales son aquellos en los que las acciones estatales buscan responder a los tres tipos de programas de cuidado de manera articulada, esto es, presentando opciones de política pública coherentes con una visión unificada sobre el problema del cuidado. Por diseños fragmentados entendemos a aquellas acciones estatales que responden a los tres componentes del cuidado de manera inconexa, buscando con las acciones estatales resolver riesgos sociales que se consideran de manera desarticulada, y no como parte central de un mismo problema social (Marzonetto 2019). En el cuadro 5 se sintetizan las principales características a observar en el diseño de las políticas de cuidado infantil para determinar si son integrales o fragmentadas. 


\section{Cuadro 5.}

\begin{tabular}{|l|l|l|}
\hline & Integral & Fragmentado \\
\hline Problema social & $\begin{array}{l}\text { Entiende al cuidado } \\
\text { como un problema } \\
\text { social }\end{array}$ & $\begin{array}{l}\text { No se piensa en } \\
\text { términos de "Cuidado" } \\
\text { Trabaja los problemas } \\
\text { sociales de manera } \\
\text { inconexa }\end{array}$ \\
\hline $\begin{array}{l}\text { Desfamiliarización } \\
\text { del cuidado }\end{array}$ & $\begin{array}{l}\text { Presenta opciones } \\
\text { estatales para su } \\
\text { desfamiliarización }\end{array}$ & $\begin{array}{l}\text { No presenta opciones } \\
\text { estatales para su } \\
\text { desfamiliarización }\end{array}$ \\
\hline Servicios en EDIs & $\begin{array}{l}\text { Jornada: en } \\
\text { consonancia con } \\
\text { horarios laborales. } \\
\text { Edad de } \\
\text { ingreso: a partir de la } \\
\text { edad de finalización } \\
\text { de licencia por } \\
\text { nacimiento }\end{array}$ & $\begin{array}{l}\text { Jornada: en } \\
\text { discordancia con los } \\
\text { horarios laborales } \\
\text { Edad de ingreso: } \\
\text { no condice con la edad } \\
\text { de finalización de la } \\
\text { licencia por nacimiento }\end{array}$ \\
\hline $\begin{array}{l}\text { Transferencias } \\
\text { condicionadas de } \\
\text { Ingresos a las } \\
\text { familias (no } \\
\text { contributivas) }\end{array}$ & $\begin{array}{l}\text { Servicios y } \\
\text { contraprestaciones a } \\
\text { certificar en jornada } \\
\text { extendida (ej. Horario } \\
\text { de controles médicos } \\
\text { desde la mañana } \\
\text { hasta la tarde) }\end{array}$ & $\begin{array}{l}\text { Servicios y } \\
\text { contraprestaciones a } \\
\text { certificar en } \\
\text { concordancia con la } \\
\text { jornada laboral de } \\
\text { padres y madres (ej. } \\
\text { Horarios de controles } \\
\text { médicos sólo de } \\
\text { mañana). }\end{array}$ \\
\hline
\end{tabular}

Diseños de políticas de cuidado infantil Elaboración propia.

\section{1. Las politicas de cuidado infantil en Argentina}

A continuación se presentan de manera sucinta las principales características de los programas de cuidado infantil en referencia a tiempo, espacios y dinero para cuidar. Esta breve descripción nos permitirá analizar con el modelo de coordinación institucional propuesto si estos programas se articulan entre sí y en qué medida lo hacen.

\subsubsection{Licencias por nacimiento}

El principal régimen de licencias en el país es el que estipula la Ley 20744 de Contrato de Trabajo (LCT), que se refiere a: licencias de maternidad, permisos de lactancia, licencia de paternidad, período de excedencia y licencias parentales. Esta ley alcanza a trabajadores formales en relación de dependencia, pero algunos sectores y categorías ocupacionales cuentan con regímenes de licencias propios, como por ejemplo el sector público nacional, las administraciones públicas provinciales, los docentes, el personal de salud y quienes trabajan en el sector agrario.

Adicionalmente, la legislación vigente sólo contempla las licencias por nacimiento pero no así por cuidado en caso de enfermedad de hijos y grupo familiar, y adaptación escolar, entre otros aspectos que comprenden el conjunto de actividades de cuidado (Rodríguez Enríquez y Marzonetto, 2015). Es decir, se deja librado el problema del cuidado y las posibilidades de encontrar estrategias 
de conciliación exclusivamente a las familias. Sumado a esto, no todos los trabajadores ni trabajadoras tienen los mismos derechos: se observa un rezago de la legislación en materia de licencias para las parejas del mismo sexo, puesto que no cuentan con los beneficios que sí tienen las parejas heterosexuales; ${ }^{6}$ y las licencias sólo están contempladas para los y las empleadas del sector formal de la economía, por lo que más de un tercio de la masa trabajadora queda por fuera de este beneficio.

Cuando analizamos los beneficios en materia de licencias parentales en las administraciones públicas provinciales, damos cuenta de diferencias significativas en cantidad y tipos de beneficio, cuestión que también ocurre con varios sectores productivos que presentan beneficios de licencias diferentes a los de la LCT. Esta situación muestra la presencia de un "mosaico legislativo" en materia de licencias por nacimiento y cuidados (Laya y Rossi, 2015), donde el acceso a este beneficio está condicionado al sector y tipo de relación laboral de las personas.

Según expertos, los problemas de coordinación en materia de licencias responden a una serie de aspectos, entre ellos, el delicado juego de negociaciones de los ejecutivos provinciales -con sus respectivas restricciones fiscales y presupuestarias- y a la relación entre estos, sindicatos y empresarios sin la conducción de una reforma por un agente catalítico central. Se observa que no se produjeron canales de coordinación institucional entre los actores políticos (gobiernos subnacionales, sindicatos y sectores empresariales) para la unificación del régimen de licencias. Asimismo, toda la discusión parlamentaria al respecto discurrió por un carril distinto al del resto de los programas de cuidado. Frente a esto, consideramos que hubo un tipo de "coordinación nula" tanto entre los diferentes regímenes de licencias como entre estos y las políticas de transferencias y de servicios de cuidado infantil.

\subsubsection{Establecimientos de desarrollo infantil (EDI)}

Los servicios de cuidado y estimulación que se brindan en los EDI varían en base a si los mismos son educativos (llamados formales) o asistenciales (llamados no formales), así como también en base a las características del contexto. Los primeros pertenecen a la órbita del sistema educativo y por ello brindan contenidos educativos y pedagógicos con objetivos curriculares obligatorios diseñados por las carteras de educación de los gobiernos provinciales, y llevados adelante por educadoras profesionales, siendo obligatorio para sala de 4 y 5 años (según lo establecido en la Ley Nacional de Educación 26206 y su modificatoria Ley 27045).

Los establecimientos asistenciales, por su parte, se focalizan sobre todo en familias en situación de vulnerabilidad social y se orientan al fortalecimiento familiar, apoyo nutricional, contención social, dejando en un segundo plano los objetivos pedagógicos, ya que el personal que trabaja con los niños no está obligado a tener formación docente, ni a seguir un plan curricular específico (Marzonetto 2016). Encontramos una variedad entre los que son de carácter comunitario y dependen de organizaciones sociales, y aquellos que pertenecen a la órbita estatal, pudiendo ser iniciativas locales, provinciales o nacionales (Faur 2014; Rozengardt 2020). 
Un aspecto importante a destacar en lo que respecta a los EDI educativos es la mayor presencia de establecimientos de gestión privada para jardín maternal (65\%) frente a las salas de 3, 4 y 5 y al nivel de educación básica (primario) según datos de la Dirección de Evaluación e Información Educativa (Ministerio de Educación de la Nación). Por su parte, en lo que respecta a la jornada de los establecimientos, la información disponible informa de la poca oferta de servicios de doble jornada (sobre todo de gestión estatal), que permitan conciliar los derechos a la educación de los niños con la posibilidad de lograr la corresponsabilidad de los cuidados entre las familias y el Estado (Mayol Lassalle, Marzonetto, y Quiróz, 2020).

A nivel nacional, el Ministerio de Desarrollo Social (MDS) cuenta con el "Plan Nacional de Primera Infancia", aprobado por decreto n574 de 2016, como herramienta para garantizar el desarrollo integral de niños y niñas de cuarenta y cinco (45) días a cuatro (4) años de edad inclusive, en situación de vulnerabilidad social y que no se encuentren incluidos en el sistema de educación formal, en pos de favorecer la promoción y protección de sus derechos (Art.1). ${ }^{7}$ Este programa, que brinda servicios en los Espacios de Primera Infancia (EPIs) tiene sus antecedentes en la Ley No26233 de Promoción y Regulación de los Centros de Desarrollo Infantil. Los lineamientos socio-educativos y de atención integral de la infancia, así como la coordinación intersectorial entre distintas agencias del Estado Nacional y de las provincias, tienen como organismo rector a la Secretaría de Niñez, Adolescencia y Familia del MDS (SENNAF).

El programa se lleva a cabo a través del trabajo conjunto del MDS, gobiernos provinciales, municipales y organizaciones comunitarias, mediante la celebración de convenios. Asimismo, se trabaja con organizaciones de la sociedad civil para poner en funcionamiento EPl adicionales, y para desarrollar espacios de estimulación aledaños a zonas rurales. El mismo es financiado en su totalidad por el Estado Nacional.

Todo esto es indicativo de problemas de coordinación a nivel jurisdiccional para brindar el mismo servicio a los niños y niñas pequeñas del país. De igual manera, la oferta de servicios tanto en EDI formales como informales muestra dificultades para responder al problema del cuidado, puesto que los establecimientos de gestión estatal que ofrecen servicios de jornada extendida en consonancia con los horarios laborales son la excepción. Ante esto, observamos que en el diseño de estos establecimientos no se pensó como una alternativa ante el problema del cuidado: permiten desfamiliarizar parcialmente el cuidado de (algunos de) los más pequeños, pero no permiten conciliar responsabilidades de cuidado y laborales de las madres, por las dificultades reales para acceder a cupos como por la limitada oferta de servicios de jornada extendida.

En relación a las instancias de coordinación de estos programas, observamos la presencia de coordinación positiva entre el MDS y el Ministerio de Educación y las carteras de educación provinciales en la cual no sólo se genera un reconocimiento de los otros programas que se llevan a cabo, sino que se trabaja en conjunto para mejorar los servicios ofrecidos, aunque cada organización mantenga sus propias metas particulares:

Como el sistema educativo oficial se muestra incapaz de cubrir toda la demanda de servicios para niños de entre 45 días y 4 años, las soluciones a este problema para las familias de menores ingresos que no acceden a cupos en 
el sistema formal, se dan por medio de establecimientos de tipo asistenciales, ya sea estatales o comunitarios (regulados por la Ley 26.233 de Centros de Desarrollo Infantil y Ley 27.064 de Regulación y Supervisión de Instituciones no incluidas en la enseñanza oficial). Esta situación fue prevista al momento de la sanción de la Ley 26.206, y en la misma se establecen instancias de coordinación interministerial para la regulación desde el Ministerio de Educación (y las carteras provinciales) de los EDI asistenciales.

Para ello, la citada ley refiere a la importancia de la vinculación entre los establecimientos de tipo asistenciales y el Ministerio de Educación a fin de garantizar que se impartan contenidos educativos mínimos en este tipo de establecimientos. Esto implica que si bien la mayoría de los EDI no incorporados al sistema educativo formal se encuentran gestionados por el MDS, el Ministerio de Educación de la Nación debe velar por que los mismos impartan contenidos educativos mínimos a los niños y niñas que asisten a estos, a fines de reducir las desigualdades en los contenidos educativos.

De todos modos, esta relación entre programas no está exenta de problemas. La dificultad para articular al Ministerio de Educación y el MDS, responde a lo que consideramos un problema de coordinación anidado. Esto se debe a: la dificultad de coordinación horizontal debido a la falta de instancias periódicas de dialogo intersectorial, que a su vez resulta en problemas para la coordinación vertical, entendiendo que los procesos de articulación entre programas implicarían la participación del MDS (con los respectivos representantes de los efectores locales de los EDI) y de las 24 carteras de educación subnacionales. Esta situación genera dificultades para la coordinación de programas, que en los casos exitosos responden a las capacidades de articulación a nivel territorial entre los efectores de los EDI y la comunidad educativa local. Lo cual implica que el éxito en la articulación entre programas al no estar institucionalizadas todas las instancias de decisión y diálogo, se encuentra supeditado a la discrecionalidad de los funcionarios en el plano local, lo que no permite garantizar la sustentabilidad de los procesos.

\subsubsection{Transferencias de dinero a familias con niños y niñas pequeñas}

En el país desde 1957 existe un sistema de asignaciones familiares contributivas, creado para "aliviar a los trabajadores de las mal llamadas cargas de familia" (Straschnoy 2011, 113). Las asignaciones incluyen beneficios mensuales que pueden recibir los trabajadores asalariados registrados, los trabajadores desocupados con seguro de desempleo y los jubilados y pensionados, por cada hijo o hija que tienen a cargo (hasta una determinada edad), y beneficios específicos por eventos vitales como matrimonio, nacimiento y adopción (Arza y Chahbenderian 2014, 9). A partir de 2009, con la creación de la Asignación Universal por Hijo para Protección Social (AUH), se unificó el sistema de asignaciones familiares, y el mismo es administrado por la Administración Nacional de la Seguridad Social (ANSES).

De este modo el esquema de transferencias de dinero a familias con hijos e hijas menores de 18 años se presenta ordenado en tres segmentos: la AUH, el esquema contributivo y la deducción fiscal, integrado y centralizado en la ANSES. (Ver cuadro 6) 
Cuadro 6.

\begin{tabular}{|c|c|c|c|c|c|c|}
\hline Transferencia & \begin{tabular}{|l} 
Condición \\
laboral de \\
padres y \\
madres \\
\end{tabular} & $\begin{array}{l}\text { Titular del } \\
\text { beneficio }\end{array}$ & $\begin{array}{l}\text { Titular efectivo del } \\
\text { pago }\end{array}$ & $\begin{array}{l}\text { Organismo } \\
\text { del } \\
\text { Estado }\end{array}$ & Normativa & \\
\hline AUH & $\begin{array}{l}\text { Trabajadores jas } \\
\text { informales. } \\
\text { Empleados/as } \\
\text { del servicio } \\
\text { doméstico. } \\
\text { Desocupadosjas } \\
\text { sin seguro de } \\
\text { desempleo. } \\
\text { Monotributistas } \\
\text { sociales. Otras } \\
\text { categorias } \\
\text { específicas no } \\
\text { cubiertas por la } \\
\text { seguridad } \\
\text { social } \\
\end{array}$ & $\begin{array}{l}\text { Hijo/Hija } \\
\text { menor de } 18 \\
\text { años }\end{array}$ & $\begin{array}{l}\text { Madre en primera } \\
\text { instancia, padre, } \\
\text { apoderado/a o } \\
\text { tutor la }\end{array}$ & ANSES & $\begin{array}{l}\text { Decreto } \\
\text { PEN } \\
1602109 \\
\text { Ley } \\
24.714\end{array}$ & No contributiva \\
\hline $\begin{array}{l}\text { Asignaciones } \\
\text { Familiares }\end{array}$ & $\begin{array}{l}\text { Asalariados/as } \\
\text { formales. } \\
\text { Beneficiarios/as } \\
\text { del seguro de } \\
\text { riesgos del } \\
\text { trabajo, seguro } \\
\text { de desempleo, } \\
\text { sistema } \\
\text { previsional y } \\
\text { pensiones no } \\
\text { contributivas. } \\
\text { Esquema } \\
\text { especial para } \\
\text { empleados/as } \\
\text { públicos/as. }\end{array}$ & $\begin{array}{l}\text { Trabajador la } \\
\text { Formal por } \\
\text { hijo/a hasta } \\
18 \text { años o } \\
24 \text { años de } \\
\text { edad si } \\
\text { continúa } \\
\text { estudiando. }\end{array}$ & $\begin{array}{l}\text { Madre en primera } \\
\text { instancia, } \\
\text { independientemente } \\
\text { de quién genere el } \\
\text { derecho, padre, } \\
\text { apoderado la o } \\
\text { tutor ja }\end{array}$ & ANSES & $\begin{array}{l}\text { Ley } \\
24.714\end{array}$ & \multirow[t]{2}{*}{$\begin{array}{l}\text { Contributiva sin } \\
\text { condicionalidades }\end{array}$} \\
\hline $\begin{array}{l}\text { Deducción } \\
\text { fiscal por } \\
\text { hijo/a en el } \\
\text { Impuesto a } \\
\text { las } \\
\text { Ganancias }\end{array}$ & $\begin{array}{l}\text { Personas } \\
\text { alcanzadas por } \\
\text { el impuesto a } \\
\text { las ganancias. }\end{array}$ & \begin{tabular}{|l|} 
Personas \\
alcanzadas \\
por el \\
impuesto a \\
las \\
ganancias \\
\end{tabular} & $\begin{array}{l}\text { Personas } \\
\text { alcanzadas por el } \\
\text { impuesto a las } \\
\text { ganancias }\end{array}$ & AFIP & $\begin{array}{l}\text { Ley } \\
24.714\end{array}$ & \\
\hline
\end{tabular}

Esquema de transferencias de dinero a familias Marzonetto (2019).

Si bien la asignación familiar contributiva es un beneficio que perciben los hijos de trabajadores asalariados sin condicionamientos, en el caso de quienes perciben la AUH, se presentan una serie de condicionalidades: los niños y niñas de hasta 4 años de edad deben cumplir con los controles sanitarios y el esquema de vacunación completo o en curso. Para los niños y adolescentes desde los 5 hasta los 18 años de edad, la condicionalidad consiste, además de las mencionadas, en acreditar la asistencia a un establecimiento escolar público. Para el control de estas condicionalidades la ANSES retiene mensualmente un $20 \%$ del monto de la prestación, hasta que se demuestre su cumplimiento. En caso de no cumplirse con alguna de las condicionalidades se da la baja del beneficiario para el año siguiente, o hasta que el mismo haya regularizado la situación (Arcidiácono, Carmona, y Straschnoy 2011).

Con todo, se observa que la unificación de las asignaciones contributivas y no contributivas dentro del sistema de seguridad social, podría ser indicativo de un mayor nivel de integración entre estas medidas. De todos modos, también encontramos que la segmentación del sistema deviene del tipo de relación, y con ello de beneficios asociados, de los padres y las madres en el mercado laboral. 
Por otra parte, la implementación de la AUH, generó relaciones interministeriales a través de sus condicionalidades de salud y educación. Puesto que para cumplir con las contraprestaciones del programa es necesario que los beneficiarios estén inscriptos en el Programa Sumar del Ministerio de Salud de la Nación y que asistan a establecimientos educativos a partir de la edad escolar obligatoria, cuestión que da crédito de un nivel de coordinación horizontal positiva. También, uno de los criterios de acceso a los EDIs no formales, es ser beneficiario de esta asignación, lo que refuerza una instancia de coordinación entre el MDS y la ANSES, para la población en situación de vulnerabilidad social.

3. 2. Análisis de grado de coordinación institucional entre programas de cuidado infantil

A continuación se analiza el grado de coordinación institucional alcanzado entre los programas a partir del modelo sugerido en la sección 2. En los cuadros donde se despliegan las dimensiones de análisis tanto para coordinación horizontal como vertical (cuadros 7 y 8) se observa la ausencia de la vinculación de los programas de transferencias y de espacios de desarrollo infantil con los de licencias. Esto se debe a que como se analiza brevemente en el apartado sobre licencias por nacimientos y cuidados, las mismas han mostrado una coordinación nula, mientras que sí se observan niveles de coordinación institucional entre los otros dos tipos de programas. 


\section{Cuadro 7.}

\begin{tabular}{|c|c|c|c|}
\hline Dimensión & Sub-dimensión & Indicador & \begin{tabular}{|l|}
$\begin{array}{l}\text { Nivel de } \\
\text { coordinación }\end{array}$ \\
\end{tabular} \\
\hline \multirow[t]{3}{*}{$\begin{array}{l}\text { Proceso de } \\
\text { formulación de } \\
\text { políticas }\end{array}$} & Diseño & $\begin{array}{l}\text { Conocimiento } \\
\text { mutuo de las } \\
\text { politicas de } \\
\text { EDIs } \\
\text { implementadas } \\
\text { por cada } \\
\text { ministerio } \\
\text { (educativos y } \\
\text { asistenciales) } \\
\text { Reconocimiento } \\
\text { a través del } \\
\text { marco } \\
\text { normativo (Ley } \\
\text { 26.206) En } \\
\text { AUH } \\
\text { cumplimiento } \\
\text { de } \\
\text { condicionalidad } \\
\text { referida a } \\
\text { escolaridad a } \\
\text { partir de nivel } \\
\text { inicial } \\
\text { obligatorio (S4 } \\
\text { Y S5) EDIs } \\
\text { (SENNAF, MDS) } \\
\text { focalizado } \\
\text { para niños } \\
\text { cuyos padres } \\
\text { perciban } \\
\text { alguna de las } \\
\text { pensiones y/o } \\
\text { asignaciones } \\
\text { no } \\
\text { contributivas } \\
\text { y desde } \\
\text { creación de } \\
\text { AUH para } \\
\text { perceptores de } \\
\text { esta } \\
\text { asignación. } \\
\end{array}$ & Positiva \\
\hline & Implementación & \begin{tabular}{|l|} 
En paralelo, se \\
cruzan los \\
destinatarios a \\
partir de sala \\
de 4 años, en \\
caso de falta \\
de vacantes en \\
EDIs formales \\
\end{tabular} & Positiva \\
\hline & Presupuesto & \begin{tabular}{|l|} 
Partidas \\
presupuestarias \\
de \\
ciministerio. \\
En el caso de \\
Educación se \\
basa en fondos \\
propios de \\
coparticipación, \\
de cada \\
provincia. En el \\
caso de CeDIs \\
de MDS se \\
basa en \\
transferencias \\
de fondos \\
desde el \\
gobierno \\
nacional a las \\
provincias, \\
municipios y/o \\
organizaciones \\
que gestionan \\
el programa \\
\end{tabular} & Positiva \\
\hline \multirow[t]{3}{*}{ Institucionalidad } & $\begin{array}{l}\text { consejo o gabinete } \\
\text { específico }\end{array}$ & \begin{tabular}{|l|} 
En el plano \\
formal existe el \\
Consejo \\
Nacional de \\
Coordinación \\
de Políticas \\
Sociales, pero \\
su intervención \\
en relación a \\
EDIs y \\
transferencias \\
durante el \\
periodo fue \\
nula. \\
\end{tabular} & Nula \\
\hline & \begin{tabular}{|l|}
$\begin{array}{l}\text { Reuniones } \\
\text { inter-ministeriales }\end{array}$ \\
\end{tabular} & Sin vigencia & Nula \\
\hline & $\begin{array}{l}\text { Legalidad de la } \\
\text { Coordinación } \\
\text { Institucional }\end{array}$ & \begin{tabular}{|l|} 
Normativas y \\
marcos legales \\
vigentes que \\
establecen \\
conocimiento \\
de los \\
programas y \\
que instan a la \\
creación de \\
mecanismos de \\
articulación: \\
Ley de \\
Protección \\
Integral de \\
Derechos de \\
Niños, Niñas y \\
Adolescentes \\
26.061 \\
\end{tabular} & Positiva \\
\hline
\end{tabular}

Nivel de coordinación horizontal entre EDIs y Transferencias 
Elaboración propia.

Cuadro 8.

\begin{tabular}{|c|c|c|c|}
\hline Dimensión & Sub-dimensión & Indicador & $\begin{array}{l}\text { Tipo de } \\
\text { coordinación }\end{array}$ \\
\hline \multirow[t]{3}{*}{$\begin{array}{l}\text { Proceso de } \\
\text { formulación de } \\
\text { Políticas }\end{array}$} & Diseño & $\begin{array}{l}\text { Consensuado con } \\
\text { Estados } \\
\text { Sub-nacionales. } \\
\text { Cada provincia } \\
\text { tiene la potestad } \\
\text { sobre los servicios } \\
\text { de educación } \\
\text { pública } \\
\text { provinciales. El } \\
\text { programa de EDIs } \\
\text { del MDS (EPI), es } \\
\text { financiado y } \\
\text { regulado por la } \\
\text { SENNAF a nivel } \\
\text { nacional y } \\
\text { ejecutado por } \\
\text { efectores locales: } \\
\text { Municipales, } \\
\text { comunitarios, de } \\
\text { oNGs, de Iglesias, } \\
\text { etc. } \\
\end{array}$ & Problemática \\
\hline & Implementación & $\begin{array}{l}\text { Espacios de } \\
\text { Primera Infancia: } \\
\text { Gestión mixta } \\
\text { entre SENNAF y } \\
\text { efectores locales. } \\
\text { EDIs educativos: } \\
\text { gestión } \\
\text { descentralizada a } \\
\text { nivel provincial }\end{array}$ & Problemática \\
\hline & Presupuesto & $\begin{array}{l}\text { EDIs educativos: } \\
\text { financiados por } \\
\text { erarios } \\
\text { provinciales y } \\
\text { fondos especiales } \\
\text { de Nación. } \\
\text { Espacios de } \\
\text { Primera Infancia: } \\
\text { de financiación } \\
\text { mixta entre } \\
\text { gobierno nacional } \\
\text { (para sueldose } \\
\text { infraestructura) y } \\
\text { gestión local de los } \\
\text { mismos. } \\
\end{array}$ & Problemática \\
\hline \multirow[t]{2}{*}{ Instituciona-lidad } & $\begin{array}{l}\text { Legado de } \\
\text { política pública } \\
\text { sectorial }\end{array}$ & $\begin{array}{l}\text { Continuación de la } \\
\text { política de Nivel } \\
\text { Inicial (de 1993) } \\
\text { con incorporación } \\
\text { de sala de } 4 \\
\text { (2015). } \\
\text { Institucionalización } \\
\text { de los EDIs } \\
\text { comunitarios } \\
\text { creados alrededor } \\
\text { de la crisis de } \\
\text { 2001-2002. } \\
\text { Tensión entre } \\
\text { servicios } \\
\text { educativos y de } \\
\text { cuidado sin } \\
\text { contenidos } \\
\text { educativos. }\end{array}$ & Problemática \\
\hline & $\begin{array}{l}\text { Forma de } \\
\text { gobierno } \\
\text { (cantidad de } \\
\text { Puntos y } \\
\text { actores de veto) }\end{array}$ & $\begin{array}{l}\text { Federal: Muchos } \\
\text { puntos y actores } \\
\text { de veto en política } \\
\text { educativa de Nivel } \\
\text { inicial de los } \\
\text { gabinetes de } \\
\text { educación } \\
\text { provinciales por } \\
\text { aspectos ligados a } \\
\text { la capacidad fiscal } \\
\text { de los estados } \\
\text { sub-nacionales }\end{array}$ & Problemática \\
\hline
\end{tabular}


Tipo de coordinación vertical a nivel subnacional sobre EDIs*

Elaboración propia.

* No se incluyen las transferencias debido a que no hubieron instancias de descentralización.

\section{Cuadro 9.}

\begin{tabular}{|c|c|c|c|}
\hline Coordinación Horizontal & Coordinación Vertical & $\begin{array}{l}\text { Coordinación } \\
\text { Institucional }\end{array}$ & $\begin{array}{l}\text { Diseño de la } \\
\text { política de } \\
\text { cuidado }\end{array}$ \\
\hline Nula entre licencias-EDIs-Transferencias & No se establece & Nula & \\
\hline Positiva entre EDIs-Transferencias & $\begin{array}{l}\text { Se establece desde el } \\
\text { gobierno central de } \\
\text { manera vertical sin } \\
\text { consenso con gobiernos } \\
\text { Subnacionales y se } \\
\text { generaron acuerdos } \\
\text { formales entre algunos } \\
\text { sectores (vinculación } \\
\text { EDIs no formales del } \\
\text { MDS y EDIs formales de } \\
\text { las carteras educativas } \\
\text { jurisdiccionales y } \\
\text { vinculación entre } \\
\text { acceso a transferencias } \\
\text { condicionadas a a EDIs } \\
\text { no formales). La } \\
\text { sustentabilidad de los } \\
\text { acuerdos entre } \\
\text { organismos no está } \\
\text { garantizada ya que } \\
\text { depende de las } \\
\text { relaciones } \\
\text { intergubernamentales. }\end{array}$ & $\begin{array}{l}\text { Incipiente y } \\
\text { débil }\end{array}$ & Fragmentado \\
\hline
\end{tabular}

Nivel de coordinación institucional entre los programas de cuidado infantil Elaboración propia.

Del análisis se advierte que el diseño de las políticas de cuidado infantil en Argentina se presenta fragmentado, y si bien se logró un nivel de coordinación horizontal positiva, la integración de políticas fue un objetivo lejano pese a los marcos normativos que abogaban por los enfoques integrales y la articulación entre organismos.

Siguiendo el esquema de análisis de niveles de coordinación propuesto por Peters (1998b), consideramos que si observamos la relación entre los programas de cuidado referidos a EDIs y transferencias de dinero durante el periodo se ha logrado un nivel de coordinación positiva en el plano de diseño. No obstante si observamos los tres tipos de programas en su conjunto (incluyendo a las licencias por nacimiento) no existen instancias de coordinación.

En este sentido, planteamos que el diseño de las políticas de cuidado infantil en Argentina es fragmentado y que el tipo de coordinación institucional que se observa es de tipo "incipiente y débil", puesto que por un lado se evidencia una instancia positiva de coordinación horizontal entre los programas de EDIs y de transferencias, aunque no así con las políticas de licencia por nacimiento. Por otro lado, en relación a la coordinación vertical se observa que muchos de los programas diseñados a los fines que aquí analizamos, se establecen desde el gobierno nacional sin el consenso con gobiernos provinciales, sobre todo en materia de EDIs no formales y de transferencias a familias. Lo cual es indicativo de que la sustentabilidad de los acuerdos entre organismos no está garantizada 
ya que depende del tipo de relaciones intergubernamentales existentes (tanto a nivel horizontal como vertical).

\section{Discusión}

El objetivo de este trabajo era analizar si los programas de cuidado infantil en Argentina se articulan entre sí y en ese caso, en qué medida lo hacen. Este ejercicio que se desarrolla a partir de la propuesta de un modelo de análisis de la coordinación institucional entre políticas sociales, está motivado por la discusión actual sobre la construcción de un sistema integrado de cuidados en el país.

Consideramos de vital importancia que se diseñe e implementen políticas que permitan hacer frente a la problemática del cuidado y sus efectos sobre las desigualdades socio-económicas y de género en la Argentina. A su vez nos parece importante comprender los límites a la capacidad de coordinación institucional que imponen las instituciones y las relaciones intersectoriales e intergubernamentales derivados de la multiplicidad de programas involucrados. Puesto que la coordinación institucional es una condición necesaria para la integralidad del sistema de cuidados por el cual se aboga.

En este sentido, el análisis se enfocó sobre la dimensión de los cuidados en la primera infancia, pero a partir del modelo propuesto podría ser extrapolable a las otras dimensiones de los cuidados (i.e. programas para personas adultas mayores, con discapacidad o dependencia severa, personas cuidadoras), o a otras interacciones entre políticas sociales aquí no exploradas.

A continuación se resume brevemente los aspectos a destacar en relación a la capacidad de coordinación institucional entre estos tres tipos de programas, considerados fundamentales para dar una respuesta integral al problema del cuidado infantil:

- Las licencias por nacimiento y cuidados se presentan fragmentadas ya que coexiste un universo de beneficios diferenciado entre sectores de empleo y por tipo de composición familiar. Durante los últimos 15 años se han reformado los regímenes de licencia por nacimiento de más de la mitad de los sectores públicos provinciales, pero en direcciones diferentes que no permiten homogenizar el beneficio entre empleados del sector a nivel nacional. También en este mismo periodo se han presentado alrededor de 200 proyectos de ley de reforma del régimen de licencias por nacimiento de la LCT, pero con sustanciales diferencias en cuanto al tipo de beneficios para madres y padres al tiempo que las discusiones al respecto no se vinculan con los otros programas de cuidado infantil (Marzonetto 2019). Cuestión que demuestra, entre otros aspectos, los problemas de coordinación en la materia responden al delicado juego de negociaciones de los ejecutivos provinciales - con sus respectivas restricciones fiscales y presupuestarias- $\mathrm{y}$ a la relación entre estos, sindicatos y empresarios sin la conducción de una reforma por un agente catalítico central que lidere la discusión en torno al tema.

- Sobre los EDI, los diversos tipos de gestión existentes, tanto para el caso de los formales como de los no formales, es indicativa de la heterogeneidad de los servicios que brindan. Más allá de esto, en relación 
a la coordinación horizontal, se observan instancias de coordinación positiva entre ambos tipos de servicios dentro de la órbita de gestión estatal. Puesto que desde el Ministerio de Educación de la Nación y el MDS se trabaja de manera conjunta sobre todo para garantizar la cobertura del nivel inicial a niños y niñas a partir de los 4 años. De todos modos, debido a que las responsables por la gestión educativa son las 24 jurisdicciones subnacionales (las provincias y la Ciudad Autónoma de Buenos Aires), resulta difícil pasar del nivel de coordinación positiva a nivel horizontal al logro de la coordinación institucional.

La relación entre los EDIs formales y no formales respondería a lo que consideramos un problema de coordinación anidado: la dificultad de coordinación horizontal debido a la falta de instancias formales de diálogo interministerial, que a su vez deviene de problemas para la coordinación vertical.

- Con respecto a las transferencias de dinero a las familias con niños pequeños, se observa que la unificación de las asignaciones contributivas y no contributivas dentro del sistema de seguridad social, podría ser indicativo de un mayor nivel de integración entre estas. De todos modos, al igual que lo que ocurre en el caso de las licencias, se encuentra que el tipo de relación laboral de madres y padres determina el tipo de beneficio y de condicionalidad. Por su parte, la implementación de la $\mathrm{AUH}$, generó también relaciones interministeriales a través de sus condicionalidades de salud y educación, presentándose así como un programa impulsor de instancias de coordinación institucional, aunque estas fueron dispuestas de manera unilateral por el gobierno central a partir del decreto de creación de esta asignación (Dec. DNU1602/2009), sin instancias previas de diálogo y consenso a nivel intergubernamental.

En este ejercicio analítico se observó que la coordinación entre políticas de cuidado infantil en Argentina es incipiente y débil, por lo tanto cada programa contiene objetivos paralelos que no necesariamente se vinculan a partir de una concepción compartida sobre el problema del cuidado, y por lo tanto del modo de dar respuestas al mismo. Podemos advertir que esta fragmentación de las políticas de cuidado infantil se relacionaría, por un lado al hecho de que el problema del cuidado infantil desde una mirada integral no estuvo presente sino hasta ahora en la agenda de gobierno, por lo que no existió un organismo que oficiara de agente catalítico liderando y coordinando las relaciones en torno a la intersectorialidad e integralidad de las políticas que aquí analizamos. ${ }^{8}$

Se destaca como positivo la existencia de programas con la potencialidad de contribuir a generar respuestas integrales al problema del cuidado infantil, el desafío, por su parte, se encuentra en: 1. Construir una mirada compartida sobre el problema del cuidado y sobre el aporte que cada política sectorial puede hacer en el desarrollo de una estrategia de gobierno en torno a este. 2. Propiciar espacios institucionalizados para el diálogo intersectorial, tanto a nivel horizontal como vertical para cimentar la capacidad de coordinación institucional y la integralidad en las políticas de cuidado. Y 3. comprender la complejidad de la coordinación anidada que presenta la forma de gobierno federal -con sus diferentes procesos de descentralización de programas en agencias estatales 
de distinto nivel jurisdiccional- para el diseño e implementación de políticas intersectoriales.

Si bien este modelo de análisis de coordinación institucional resulta útil para ofrecer pistas sobre los desafíos de cara a la construcción de un sistema integral de cuidados así como para la realización de un diagnóstico de las dinámicas de gestión intersectorial multinivel en los procesos de formulación e implementación de políticas, el análisis no está exento de limitaciones. En primer lugar, porque es un modelo inacabado y se requeriría poner a prueba el modelo analítico con otros conjuntos de políticas sociales para realizar ajustes en las dimensiones e indicadores de análisis. Y en segundo lugar, porque en el caso particular de las políticas de cuidado infantil se trata de analizar las posibilidades de coordinación institucional entre programas que desde los estudios del cuidado se plantea desde un plano normativo que deben estar coordinados pero que en la práctica no necesariamente se vinculan entre sí -lo que no implica que no puedan tener mejores niveles de coordinación institucional con otros tipos de programas aquí no analizados-.

Con todo, consideramos que la contribución de este trabajo radica en que, por un lado presenta un análisis basado en evidencia sobre un conjunto de políticas sociales altamente demandadas en la actualidad haciendo uso de conceptos y herramientas del campo de la administración pública; y por otro lado, en el esfuerzo por problematizar la complejidad de la descentralización de programas sociales, y de arrojar luz sobre los desafíos de coordinación anidada implícitas en el diseño de políticas públicas integrales.

\section{Agradecimientos}

Agradezco a Julián Bertranou por sus lecturas previas y comentarios sobre este documento así como por incentivarme a presentarlo para su publicación, y a Carlos Acuña, por su guía y aportes -entre ellos el pensar el concepto de "coordinación anidada"- durante el proceso de construcción del diseño del modelo de análisis propuesto. También agradezco la lectura detallada, los comentarios y sugerencias de los revisores anónimos, que sin dudas permitieron mejorar el trabajo.

\section{Referencias}

Acuña, Carlos H. 2017. “'La coordinación como un doble desafío para las políticas públicas"'. En Los Desafíos del Bicentenario: Argentina 1816-2016, Buenos Aires, Argentina: Saguir, Julio, 213-21.

Acuña, Carlos H., y Fabián Repetto. 2006. La Institucionalidad de las Politicas y los Programeas de Reducción de la Pobreza en America Latina.

Agranoff, Robert. 1993. "Las relaciones intergubernamentales y el Estado de las Autonomías". Política y Sociedad 13: 87-105.

Agranoff, Robert. 1997. "Las relaciones y la gestión intergubernamentales". En La nueva administración pública, eds. $\mathrm{R}$ Bañón y E Carrillo. https://www.researchgate.net/profile/Ernesto_Carrillo/ publication/44459469_La_nueva_administracion_publica_Rafael_Banon_y_Ernesto_Carri links/56b4a23308ae922e6c02045c.pdf. 
Arcidiácono, Pilar, Verónica Carmona, y Mora Straschnoy. 2011. "La asignación universal por hijo para protección social: rupturas y continuidades ¿̇hacia un esquema universal?" Margen: 1-16.

Arza, Camila, y Florencia Chahbenderian. 2014. Programas de transferencias monetarias a las familias\#: Las experiencias de Argentina, Bolivia, Brasily Chile. Buenos Aires.

Blofield, Merike, y Juliana Martínez Franzoni. 2014. “Trabajo, Familia y cambios en la política pública en América Latina: Equidad, Maternalismo y corresponsabilidad". Revista de la CE: 107-25.

Borja, Jordi. 2007. "Descentralización. Una cuestión de método". En Lecturas sobre el Estado y las políticas públicas: Retomando el debate de ayer para fortalecer el actual, ed. Carlos H. Acuña. Buenos Aires: Jefatura de Gabinete de Ministros, 243-62.

Campbell, John. 2002. "Ideas, politics, and public policy". Annual Review of Sociology 28: $21-38$.

Carrasco, Cristina. 2003. "La sostenibilidad de la vida humana\#: ¿un asunto de mujeres?" En Mujeres y Trabajo: Cambios impostergables, Porto Alegre: Veraz Comunicação, 5-25. http://creativecommons.org/licenses/by-nc-nd/2.0/ deed.es\%0ATitulo.

Cunill-Grau, Nuria. 2005. "La intersectorialidad en el gobierno y gestión de la política social". En X Congresso Internacional del CLAD sobre la Reforma del Estado y de la Administración Pública, Santiago de Chile, 52. http://www.bdp.org.ar/facultad/ posgrado/maestrias/gp/documentos/Cunill.pdf.

Cunill-Grau, Nuria. 2016. "A intersetorialidade nas novas políticas sociais: uma abordagem analítico-conceitual". Cuadernps de Estudos. Desenvolvimento social em debate (26): 33-66.

Ellingsaeter, Anne Lise. 1999. "Dual Breadwinners: Between State and Market". En Restructuring Gender Relations and Employment. The Decline of the Male Breadwinner, ed. Rosemary Crompton. New York: Oxford University Press.

Esping-Andersen, Gosta. 2010. The incomplete revolution. Adapting to women's new roles. 2nd ed. Cambridge: Polity Press.

Esping-Andersen, Gosta, y Bruno Palier. 2011. Los tres grandes retos del Estado de bienestar. Barcelona: Editorial Ariel.

Falleti, Tulia G. 2005. "A sequential theory of Descentralization: Latin American cases in comparative perspective”. American Political Science Review 99(3): 327-46.

Falleti, Tulia. 2007. "Federalismo y descentralización educativa en la Argentina. Consecuencias (no queridas) de la descentralización del gasto en un país federal". En El federalismo electoral argentino: sobrerrepresentación, reforma politica y gobierno dividido en la Argentina, eds. Ernesto Calvo y Juan Manuel Aval Medina. Buenos Aires, 227-51.

Faur, Eleonor. 2014. El cuidado infantil en el Siglo XXI. Mujeres malabaristas en una sociedad desigual. Buenos Aires, Argentina: Siglo Veintiuno editores.

Immergut, Ellen M. 2008. "Political Institutions". En The Oxford Handbook of Political Institutions, eds. Sarah Binder, R.A.W Rhodes, y A Rockman. New York: Oxford University Press, 227-40.

Laya, Ana, y Felicitas Rossi. 2015. Aportes para la discusión legislativa sobre reformas necesarias en materia de cuidado. Buenos Aires.

Licha, Isabel, y Gerardo Molina. 2006. "Coordinación de la Política Social\#: criterios para avanzar”. Banco Interamericano De Desarrollo 1999: 18-21.

Martinez Nogueira, Roberto. 2010. "La coherencia y la coordinación de las políticas públicas. Aspectos conceptuales y experiencias". En Los desafios de la coordinación 
y la integralidad de las politicas y gestión pública en América Latina, ed. Carlos H. Acuña. Buenos Aires: Proyecto de Modernización del Estado. Jefatura de Gabinete de Ministros de la Nación, 9-12.

Marzonetto, Gabriela. 2016. Educación Inicial y servicios asistenciales para la primera infancia en la Ciudad de Buenos Aires\#: derechos universales, servicios estratificados. Buenos Aires.

Marzonetto, Gabriela. 2019. "La política de los programas de cuidado infantil en América Latina: Un análisis comparado de Argentina , Chile y Uruguay (2005-2015 )". Universidad Nacional de San Martín.

Mayol Lassalle, Mercedes, Gabriela Marzonetto, y Analía Quiróz. 2020. La Educación Inicial en los Sistemas Educativos Latinoamericanos para los Niños y Niñas de 3, 4 y 5 años. Buenos Aires.

Morel, Nathalie, Bruno Palier, y Joakim Palme. 2012. "Beyond the welfare state as we knew it?" En Towars a social investment welfare State, ed. Joakim Morel, Nathalie, Palier, Bruno and Palme. Bristol: The Policy Press, 33-90.

O 'Toole, Laurence J. Jr. 2007. “Interorganizational Relations in Implementation”. En The handbook of public administration. Concise Paperback Edition, eds. B. Guy Peters y Jon Pierre. London: Sage Publications, 142-52.

Orloff, Ann Shola. 2006. "From Maternalism to 'Employment for all': State policies to promote women's employment across the affluent democracies". En The State after statism, ed. Johan Levy. Harvard University Press, 1-59.

Peters, B. Guy. 1998a. 76 Public Administration Managing horizontal government: the politics of co-ordination.

Peters, B Guy. 1998b. "The Search for Coordination and Coherence in Public Policy: Return to the Center?”

Rodríguez Enríquez, Corina, y Gabriela Marzonetto. 2015. "Organización social del cuidado y desigualdad: el déficit de políticas públicas de cuidado en Argentina”. Perspectivas de Politicas Públicas 4(8): 105-34.

Rodriguez Enríquez, Corina, y Laura Pautassi. 2014. La organización social del cuidado de niños y niñas. Elementos para la construcción de una agenda de cuidados en Argentina. ed. Rodriguez Enriquez y Pautassi. Buenos Aires, Argentina: Equipo Latinoamericano de Justicia y Género: ELA.

Rodríguez Enríquez, Corina, y Laura Pautassi. 2014. La organización social La organización social del cuidado de niños y niñas.

Rossel, Cecilia, y Diego Hernandez. 2013. "Cuidado infantil, tiempo y espacio: el transporte y la frontera del acceso". En Las fronteras del cuidado. Agenda, derechos e infraestructura, eds. Laura Pautassi y Carla Zibecchi. Buenos Aires: Biblos, 35384.

Rothstein, Bo. 2007. "Political legitimacy for public administration". En Handbook of Public Administration, eds. Guy Peters y Jon Pierre. London: Sage Publications, 213-22.

Rozengardt, Adrián. 2020. Lo no formal en la atención y educación de la primera nfancia en América Latina. Análisis comparado. Buenos Aires, Argentina.

Straschnoy, Mora. 2011. “Asignación Universal por Hijo para Protección Social y Nuevo Régimen de Asignaciones Familiares\#: un análisis comparativo de los casos de Argentina y Uruguay". : 111-28.

Tronto, Joan C. 1987. "Más allá de la diferencia de género. Haia una teoría del cuidado". Journal of women in Culture and Society 12: 1-17. 
Notas

1 En julio de 2020 se creó la mesa interministerial de políticas de cuidado cuya coordinación ejecutiva está a cargo del Ministerio de Mujeres, géneros y diversidad. En noviembre del mismo año se creó la comisión redactora del anteproyecto de Ley para un sistema integral de cuidados con perspectiva de género.

2 Si bien estas tareas y responsabilidades son dinámicas y están presentes durante toda la vida, existen tres poblaciones que se destacan por ser dependientes netas de cuidado, dado que para su subsistencia necesitan inexorablemente de la asistencia de otras personas: estos son los niños y niñas en la primera infancia, las personas adultas mayores con algún tipo de limitación permanente y las personas enfermas o con discapacidad con dependencia severa. Estas tres poblaciones son distintas y por lo tanto requieren de atenciones y servicios diferentes.

3 Traducción libre.

4 La inspiración en la idea de juegos anidados de Tsebelis trae también a colación la necesidad de reconocer la importancia que adquieren los actores de veto tanto del plano nacional como sub-nacional en las instancias de coordinación.

5 En este trabajo no se abordará la diferencia entre los modelos de cuidado, pero los mismos pueden diferenciarse por el grado en que reproducen roles de género y de la familia, en modelos que tienden al maternalismo y modelos que tienden hacia la corresponsabilidad (Ver: Blofield y Martinez Franzoni 2014, Marzonetto 2019).

6 Excepto en el caso de las licencias por nacimiento para el empleo público de Tierra del Fuego donde las parejas del mismo sexo son contempladas para el beneficio.

7 Información extraída de http://www.sipi.siteal.org/normativas/1267/decretono-5742016-plan-nacional-de-primera-infancia. (última visita 15/05/2020)

8 En junio de 2020 se designó al Ministerio de Mujeres, Géneros y Diversidad como organismo coordinador de las políticas que integrarían al sistema de cuidados. 